\title{
EFFECT OF AGGREGATE GRADATION ON THE STIFFNESS OF ASPHALT MIXTURES
}

Hasan Al-Mosawe, Nick Thom \& Gordon Airey, Nottingham Centre for Pavement Engineering, School of Civil Engineering, University of Nottingham, University Park, Nottingham NG7 2RD, UK. Email: evxhmal@nottingham.ac.uk, nicholas.thom@nottingham.ac.uk \& gordon.airey@nottingham.ac.uk

Amjad Al-Bayati, Department of Civil Engineering, University of Baghdad, Baghdad, Iraq. Email: sirtransportation@yahoo.com

doi: 10.1515/ijpeat-2015-0008

\begin{abstract}
Aggregate gradation plays an important role in the behaviour of asphalt mixtures. Packing of aggregate is a very important factor that will be affected by changing the aggregate gradation. Many researchers have investigated different ways of describing packing both theoretically and practically. Bailey ratios have recently been used to understand the volumetric properties of mixtures. In this paper, the Bailey ratios have been used, and two further ratios have also been introduced to allow the asphalt mixture gradation to be fully understood. Thirteen different aggregate gradations have been chosen within the $14 \mathrm{~mm}$ asphalt concrete specification to investigate the effect of particle size distribution on the stiffness of the mixture. It was found that variation in aggregate gradation has a significant effect on asphalt stiffness, even within specification limits, and a reasonable correlation between the set of ratios investigated and the Indirect Tensile Stiffness.
\end{abstract}

\section{INTRODUCTION}

Aggregate gradation plays a very important role in the performance of an asphaltic mixture. Packing of aggregate particles is the most common way to understand how the aggregate can be structured. Many researchers have examined the packing of particles. Many researchers studied the maximum density of single sized particles and then they reached to the idea of particle gradation and then they calculate the maximum density. According to (Miranda, 2012), a good gradation for an asphalt mixture is one that gives the densest packing of particles, increasing stability by increasing the number of contact points between particles and by reducing air voids, and many attempts have been made in the past to understand the best gradation of particles to achieve the densest possible packing. Mixing variations of stones and sand particles to give the densest concrete was first examined by (Fuller and Thompson, 1907). The conclusion of their study was to relate the sand particle size to the coarse particle size and they proposed that the sand particle diameter should not exceed onetenth of the coarse particle diameter to achieve a dense concrete mixture. They also concluded that the coarser the aggregate used, the coarser the sand particle that was required. Following their work, (Talbot and Richart, 1923) studied the gradation (size distribution) of aggregate to achieve the maximum density of a mix. A slope of 0.5 on a straight line when plotting percent passing a sieve versus the particle size on logarithmic scales was considered to give maximum density. The formula for obtaining the maximum density line was: 


$$
P=100\left(\frac{d}{D}\right)^{n}
$$

Where $P$ is the percentage of material by weight passing a specific sieve with an opening size d; $D$ is the maximum particle size; and $n$ is a parameter affecting the coarseness or fineness of the gradation. (Nijboer, 1948) studied the effect of particle size and shape in asphalt mixtures. He confirmed the idea of the maximum density line given by a straight line on logarithmic scales of percent passing a sieve versus sieve size. He empirically proved that with typical stone particles the maximum density line has an approximate slope of 0.45 .

The stiffness of asphaltic mixture is highly affected by changing aggregate gradation and a study of this effect is required to be discovered. The coarse aggregate particles have very influence on the behaviour of mixture under stresses, so their effect will be considered. This paper will focus on the effect of changing aggregate gradation on the stiffness of asphalt mixture. Thirteen gradations are considered in this paper to investigate the effect of them on the stiffness of the asphalt mixture. The aim of this paper is to understand the effect of aggregate gradation on the stiffness of asphalt mixtures. This aim will be achieved by using some of Bailey ratios and introducing two new ratios to fully define the aggregate gradation of the mixture. The ratios will be used to analyse the particle size distribution and how dense the mixture is.

\section{Bailey Method}

The Bailey method was first developed by Mr. Robert Bailey from Illinois Department of Transportation. It is an approach of blending aggregate to provide good aggregate interlock. Bailey proposed ratios to evaluate the performance of a mixture. The Bailey method considers two principles in evaluating a mixture: aggregate packing and the definition of coarse and fine aggregate. In terms of aggregate packing, it is not possible to pack the aggregate particles to completely fill a certain volume. There are certain factors affecting the degree of packing, for example, gradation, particle strength, particle surface texture and shape, and finally the compaction effort. With regard to coarse and fine aggregate, there are several methods for defining the coarse and fine fractions. However, Bailey proposed a more specific and meaningful way to define them. The coarse aggregate particles are defined as those particles retained on a specific sieve size and the fine aggregate consists of particles that can fill the voids in the coarse aggregate. Certain size ratios (described below) will be used in this project to evaluate the performance of British standard gradations of asphalt concrete mixtures.

\section{Control Sieves}

The Bailey method suggests three main control sieves to classify the particles in a certain gradation. The Primary Control Sieve (PCS) is the name of the sieve that is used to separate the coarse and fine aggregate and it is based on the Nominal Maximum Particle Size (NMPS) of the aggregate blend, (Vavrik, 2002). The Bailey method was initially applied to a set of US sieves; in this project the sieve set used will be the UK sieve set. The PCS can be defined as the closest standard sieve to the result of Equation 2.

$$
\text { PCS }=\text { NMPS } \times 0.22
$$


Where

PCS $=$ PCS for the overall blend

NMPS = NMPS for the overall blend; it is defined by Superpave as one sieve larger than the first sieve on which more than $10 \%$ of the aggregate retained.

The value of 0.22 has been proposed by some researchers e.g. (Kim et al., 2006) who made use of packing theories. The Bailey method suggests this value as an average of particle diameter ratios that theoretically range from 0.15 (round particles) to 0.29 (flat particles), see Figure 1, (Olard and Perraton, 2010).

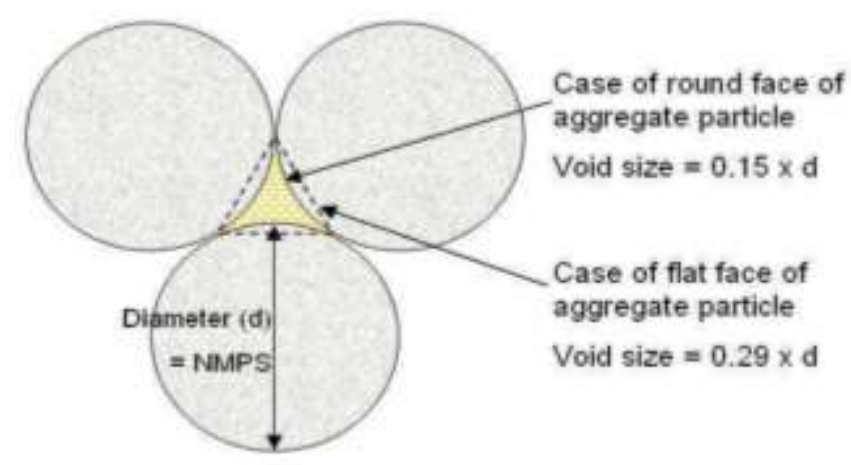

Figure 1: Two Dimensional Aggregate Packing Model by Bailey, (Olard and Perraton, 2010)

The fine fraction (passing the PCS) is then split into two further fractions by using the secondary control sieve (SCS). The value of 0.22 is used again to create the SCS, see Equation 3.

$$
\text { SCS }=\text { PCS } \times 0.22
$$

The fine material is then further divided with reference to a Tertiary Control Sieve (TCS) which is again determined using the 0.22 factor applied to the SCS, see Equation 4.

$$
T C S=S C S \times 0.22
$$

Figure 2 illustrate the control sieves in a gradation. 


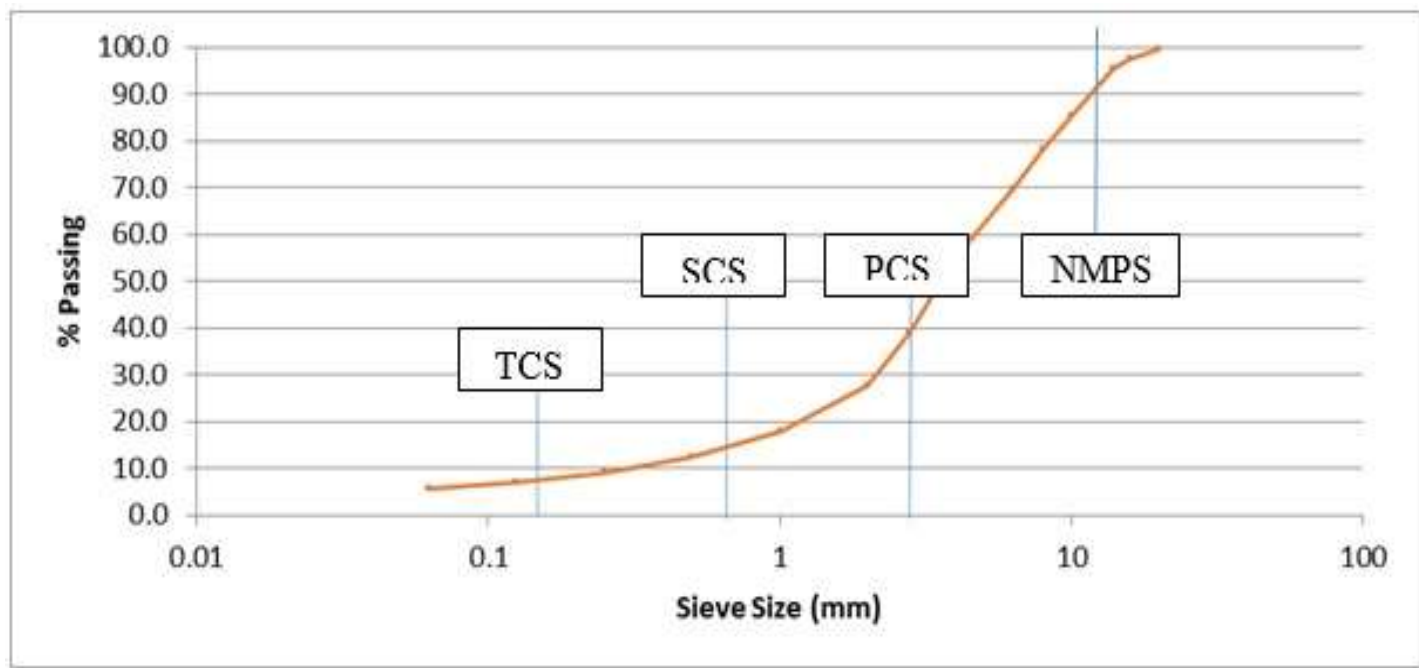

Figure 2: Bailey Control Sieves

\section{Bailey Ratios and Analysis Method}

The Bailey method is not limited to aggregate blending only; it suggests certain ratios to evaluate the blend. These evaluation ratios will be used to analyse and understand the aggregate structure of the gradations used in this project. The aggregate gradation is divided into three portions, the coarse portion which consists of aggregate sizes larger than the PCS, the coarser part of fines fraction, between the PCS and SCS, and the fine part of fines fraction which is between the SCS and TCS.

By using the above definition of sieves, three ratios were suggested by Bailey: Coarse Aggregate Ratio (CA Ratio), Fine Aggregate Coarse Ratio $\left(F_{c}\right)$, and the Fine Aggregate Fine Ratio $\left(\mathrm{FA}_{\mathrm{f}}\right)$.

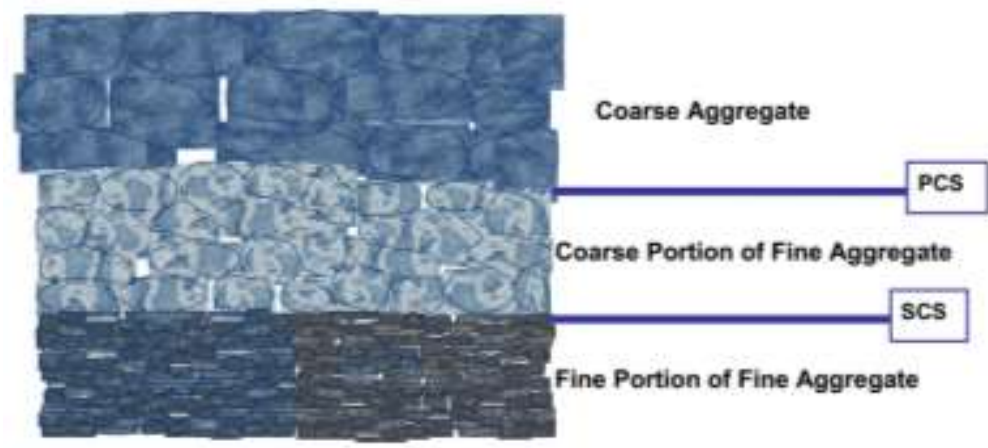

Figure 3: The Three Fractions of the Gradation (Vavrik, 2002)

\section{CA Ratio}

The CA Ratio is used in this research to evaluate the interlock of the coarse aggregate and also to understand the void structure in the coarse part of the gradation. To achieve more understanding of the coarse aggregate structure, a Half Sieve is introduced, (Vavrik, 2002). The Half Sieve (HS) is defined as half of the NMPS. Those particles smaller than the HS and larger than the PCS are termed 'interceptors'. Interceptors play an important role in mixture volumetric properties. By changing the proportions of interceptors the VMA will be changed. Interceptor particles cannot fill 
all the voids created by the larger particles because of their relatively large size compared to the voids created. However, the shape, elongation and orientation of the particles are all factors affecting the filling of the voids between coarse particles and interceptors. The CA ratio is given by Equation 5 below:

$$
C A=\frac{\% \text { Passing HS }-\% \text { Passing PCS }}{100 \%-\% \text { Passing HS }}
$$

(Vavrik et al., 2001) related the CA ratio to the ability of a mixture to compact. They suggested that in mixtures that have low CA ratios (below $\sim 1.0$ ); the compaction of the fine aggregate will improve relative to these with higher CA. However, this suggested value of CA (1.0) ratio means there are equal amounts of interceptors and coarser aggregate and they suggested that there will therefore be interlock between them and this will increase the degree of compaction. Higher values of CA ratio imply excessive amounts of interceptor particles which they suggest might lead to segregation among the particles larger than the PCS. This would lead to a noncompactible mix. Such mixes with high $\mathrm{CA}$ ratio generally have a pronounced $\mathrm{S}$ shaped gradation (as will be proved later).

\section{FAc Ratio}

The aggregate passing the PCS induces a wide blend of particle sizes. Similar to the coarse part of the blend, the coarser part of the fine fraction will induce voids between the particles and these voids will be filled by the finer particles. FA ${ }_{C}$ describes the ratio of theses fractions and Equation 6 below represents the definition of this ratio.

$$
F A c=\frac{\% \text { Passing SCS }}{\% \text { Passing PCS }}
$$

It is recommended that FAC should not be too high (no more than 0.5) as this will lead to excessive amounts of fine material in the mix. On the other hand, very low values of this ratio mean there is low content of fine material which means that the gradation is not uniform.

\section{FAf Ratio}

This ratio represents the content of the very finest material (including filler) in the mix and is important for certain aspects of mixture behaviour (e.g. voids in fine fraction, binder demand). However, this ratio will not be considered here as this project is focusing on coarse aggregate effects on permanent deformation.

\section{New Ratios}

From an analysis of the gradations used, it has been found that the two Bailey ratios are not sufficient to give a full understanding of aggregate structure and interlock. For this reason it was necessary to develop two new ratios. One gap in knowledge was in the voids among the interceptor particles and the interlock between particles in the fine fraction with the interceptors. Also there was no clear representation of the dominant particle size transferring load. These two gaps in knowledge were filled by introducing two new ratios: $\mathrm{C}_{\mathrm{f}} / \mathrm{F}_{\mathrm{c}}$ and $\mathrm{F} / \mathrm{C}$. The first is a representation of how much the coarse particles in fine fraction interact with and fill the voids in the interceptor fraction. The definition of this ratio is given by Equation 7 . 


$$
C_{f} / F_{c}=\frac{\% \text { Passing PCS }-\% \text { Passing SCS }}{\% \text { Passing } H S-\% \text { Passing PCS }}
$$

The $\mathrm{F} / \mathrm{C}$ ratio gives an indication of the relative percentages of the fine and coarse materials which will help in understanding which size range of aggregate is most active in transferring the applied load. The $\mathrm{F} / \mathrm{C}$ formula is simply the ratio of fine to coarse materials as they are defined by the Bailey method, (see Equation 8).

$$
F / C=\frac{\% \text { Passing PCS }}{\% \text { Passing NMPS }-\% \text { Passing PCS }}
$$

The above four ratios (excluding FAf) will be used to understand the packing of aggregate in the mixture.

\section{Material and Gradations}

Asphalt concrete mixture has been chosen to be used in this research. Thirteen gradations have been picked within the specification limits and fixed binder content has been used $(5.1 \%)$. The details of the mixtures gradation are shown in Table 1 below. Three samples of each gradation were manufactured by the gyratory with fixed target air voids of $5.0 \%$. Obviously not all the mixtures can reach to this target depending on the particle size distribution of each mixture. The bulk specific gravity was also measured for the samples by using the foil density method. The Indirect Tensile Stiffness Modulus (ITSM) test was performed for all the samples (three of each gradation) at $20{ }^{\circ} \mathrm{C}$. According to BS EN 12697-26, 2004 the samples were conditioned for at least 7 hours. Standard test conditions were used: $5 \mu \mathrm{m}$ target horizontal deformation, $124 \mathrm{~ms}$ rise time. A Poisson's ratio of 0.35 was assumed. The tests were carried out at the University of Nottingham.

\section{Results and Discussion}

The volumetric properties are shown in are shown in Table 1, it can be noticed that the analysis ratios have the effect on the mixture properties. For instance, as the $C_{f} / F_{c}$ ratio increases the stiffness of the mixture increase as well, see Figure 4. The reason behind this is that this ratio show how much does the interceptors particle range are connected to each other and voids between them are filled by the smaller particles. However, this is not only the ratio which describes the aggregate gradation; the other ratios should be considered to fully understand the structure of the aggregate. 
Table 1: Mixture Gradations and Results

\begin{tabular}{|c|c|c|c|c|c|c|c|c|c|c|c|c|c|}
\hline & Mix 1 & Mix 2 & Mix 3 & Mix 4 & Mix 5 & Mix 6 & Mix 7 & Mix 8 & Mix 9 & $\begin{array}{c}\text { Mix } \\
10\end{array}$ & $\begin{array}{c}\text { Mix } \\
11\end{array}$ & $\begin{array}{c}\text { Mix } \\
12\end{array}$ & $\begin{array}{c}\text { Mix } \\
13\end{array}$ \\
\hline Sieve $\mathrm{mm}$ & \multicolumn{13}{|c|}{$\%$ Passing } \\
\hline 20 & 99 & 99.9 & 99.8 & 100 & 99.7 & 100 & 99.3 & 99.3 & 100 & 100 & 100 & 100 & 98.7 \\
\hline 16 & 92.8 & 98.6 & 98.1 & 99.9 & 97.6 & 99.5 & 95.3 & 95.1 & 99.8 & 99.6 & 99.5 & 99.4 & 90.7 \\
\hline 14 & 86.7 & 95 & 94.2 & 99.2 & 95.3 & 96.3 & 91.8 & 90.1 & 98.4 & 97.4 & 96.2 & 95.9 & 84.1 \\
\hline 10 & 66 & 70.7 & 72.1 & 89.6 & 86.2 & 75.2 & 80.8 & 69.4 & 88 & 81.3 & 73.7 & 71.9 & 67.1 \\
\hline 8 & 58 & 58 & 66.6 & 76.3 & 78.4 & 70.5 & 70.3 & 56.2 & 78.6 & 69.4 & 63.2 & 64.4 & 62.7 \\
\hline 6.3 & 48.4 & 44.7 & 60.1 & 57.3 & 66.5 & 66.3 & 56.1 & 41.9 & 66.1 & 56 & 53.2 & 58.8 & 58.6 \\
\hline 4 & 29.4 & 33.1 & 38.8 & 33.1 & 42.9 & 51.9 & 39.1 & 33.1 & 50.1 & 47.6 & 47 & 53.4 & 50.5 \\
\hline 2.8 & 23.5 & 27 & 31.3 & 24.4 & 35.2 & 45.7 & 33.9 & 30.8 & 44.6 & 44.5 & 44.2 & 45.7 & 46.4 \\
\hline 2 & 19.1 & 19.3 & 24.8 & 16.9 & 27.7 & 36.2 & 26.7 & 25.1 & 36 & 35.7 & 35.5 & 33.8 & 37.5 \\
\hline 1 & 14.2 & 11.7 & 17 & 10.2 & 18.4 & 23.1 & 17 & 16.9 & 24.2 & 22.8 & 22.8 & 22 & 24.6 \\
\hline 0.5 & 11.4 & 8 & 12.6 & 7 & 13.1 & 15.3 & 11.5 & 12.1 & 17.3 & 15.1 & 15.1 & 15.9 & 17 \\
\hline 0.25 & 9.8 & 5.6 & 9.8 & 5.1 & 9.8 & 10.6 & 8.1 & 9.1 & 13.1 & 10.4 & 10.4 & 12 & 12.3 \\
\hline 0.125 & 8.6 & 4.1 & 8 & 3.8 & 7.6 & 7.3 & 5.7 & 7 & 10.2 & 7.2 & 7.2 & 9.6 & 9.1 \\
\hline 0.063 & 7.8 & 3.2 & 6.8 & 3 & 6.2 & 5.4 & 4.3 & 5.7 & 8.4 & 5.3 & 5.2 & 8.2 & 7.2 \\
\hline \multicolumn{14}{|c|}{ Gradation Ratios } \\
\hline CA & 0.63 & 0.50 & 0.87 & 1.28 & 1.35 & 0.72 & 0.80 & 0.36 & 1.00 & 0.49 & 0.33 & 0.41 & 0.36 \\
\hline Fac & 0.49 & 0.29 & 0.40 & 0.29 & 0.37 & 0.34 & 0.34 & 0.39 & 0.39 & 0.34 & 0.34 & 0.35 & 0.37 \\
\hline $\mathrm{Cf} / \mathrm{Fc}$ & 0.41 & 0.78 & 0.58 & 0.4 & 0.59 & 1.34 & 0.76 & 1.02 & 0.99 & 1.62 & 2.09 & 1.9 & 2.07 \\
\hline $\mathrm{F} / \mathrm{C}$ & 0.37 & 0.40 & 0.50 & 0.3 & 0.58 & 0.90 & 0.58 & 0.52 & 0.83 & 0.84 & 0.85 & 0.9 & 1.23 \\
\hline \multicolumn{14}{|c|}{ Volumetric Properties } \\
\hline $\begin{array}{l}\text { Density } \\
\mathrm{kg} / \mathrm{m} 3\end{array}$ & 2266.3 & 2235.8 & 2343 & 2157.5 & 2263.3 & 2290 & 2344.3 & 2392.3 & 2373.5 & 2384.7 & 2404.3 & 2443.6 & 2449.3 \\
\hline$\%$ Air voids & 12.124 & 13.5 & 9.2915 & 16.8 & 11.3 & 11.309 & 9.3101 & 7.3098 & 8 & 7.6784 & 6.8449 & 5.1 & 4.8433 \\
\hline VMA & 23.363 & 23.992 & 20.934 & 27.523 & 23.719 & 22.717 & 20.961 & 19.146 & 19.854 & 19.523 & 18.8 & 17.297 & 16.992 \\
\hline \multicolumn{14}{|c|}{ Stiffness } \\
\hline ITSM MPa & 4809.3 & 4825 & 5983.7 & 5509.3 & 4858 & 5798 & 6560 & 6560.7 & 6819 & 6717 & 7149.3 & 11359 & 8104 \\
\hline
\end{tabular}


By comparing the four ratios of mix 1 and mix 13 one can notice:

Mix 1 has got more interceptors in coarse aggregate than mix 13 but it is not filled with the smaller particles because of the $C_{f} / F_{c}$ ratio. This makes mix 1 more voided and less stiff than mix 13.

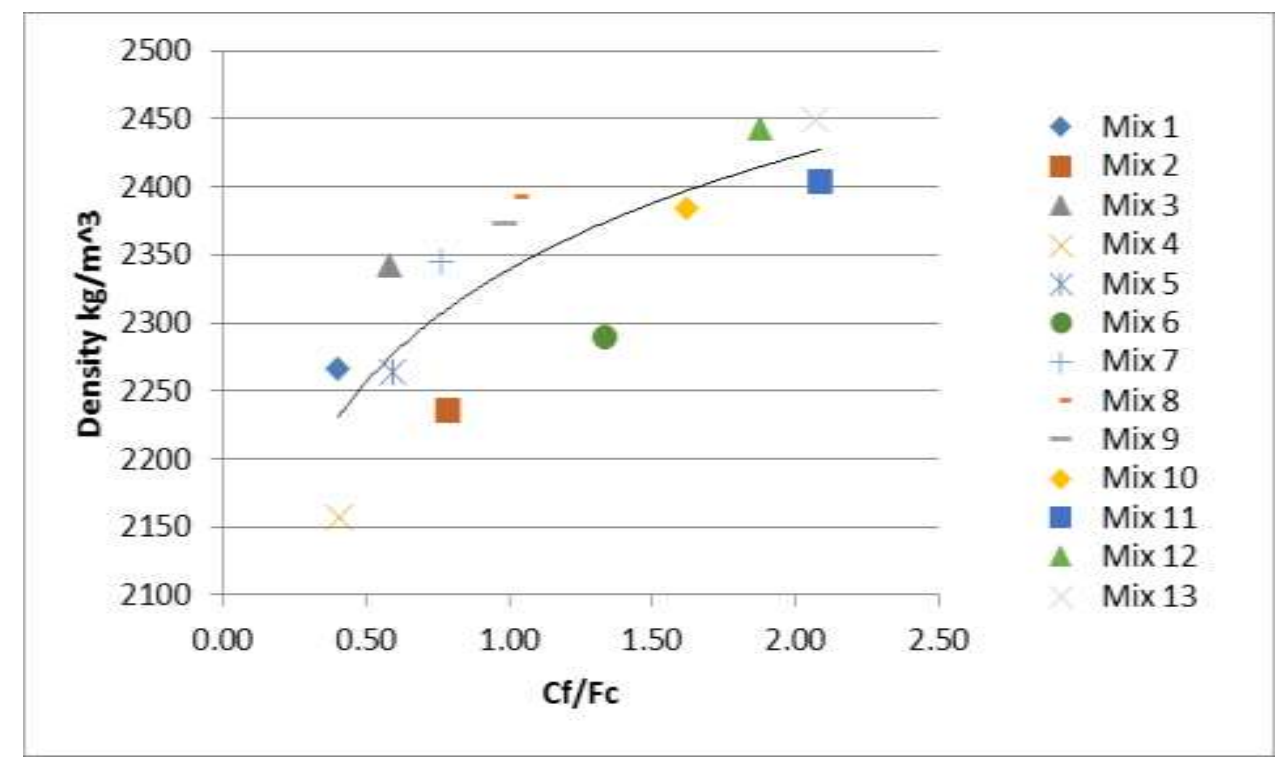

Figure 4: The Relationship between Cf/Fc and the Density

As the $\mathrm{C}_{\mathrm{f}} / \mathrm{F}_{\mathrm{c}}$ and $\mathrm{F} / \mathrm{C}$ ratio increase, the mixture becomes denser as illustrated previously so the density increases. Figure 5 shows the effect of the increase in density to the stiffness of the mixtures.

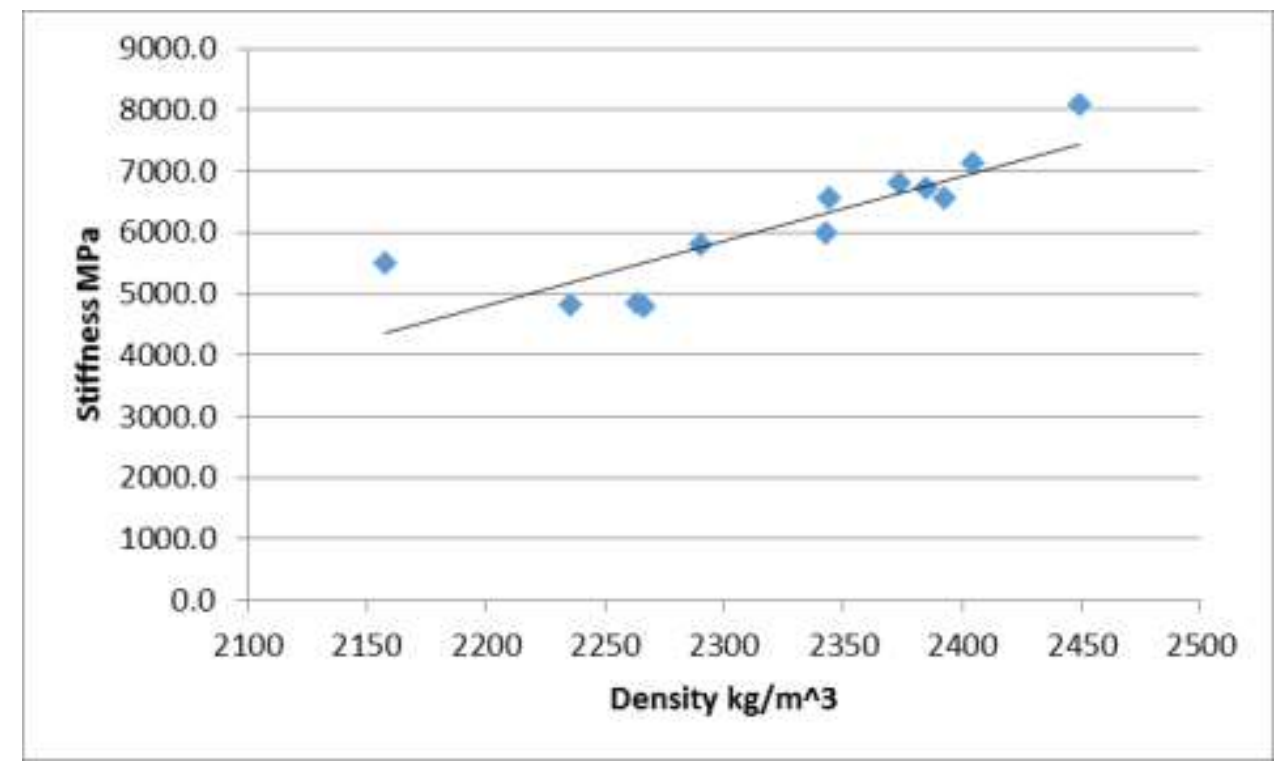

Figure 5: Effect of Density on the Stiffness 


\section{Stiffness Model}

Researchers in the past found that the Voids in Mineral Aggregate (VMA) is the most effective parameter on the mixture properties. The VMA is simply "the percentage of mixture that is not aggregate", (Thom, 2008). A stiffness model related to VMA was found by (Brown, 1978):

$$
E_{\text {mix }}=E_{\text {binder }}\left[1+\frac{257.5-2.5 V M A}{n(V M A-3)}\right]^{n}
$$

Where:

$n=0.83 \log \left[\frac{4 \times 10^{4}}{E_{\text {binder }}}\right]$

The above model was used to predict the mixture stiffness by assuming the binder stiffness to be $140 \mathrm{MPa}$; Figure 6 shows the predicted and measured stiffness for Brown's model:

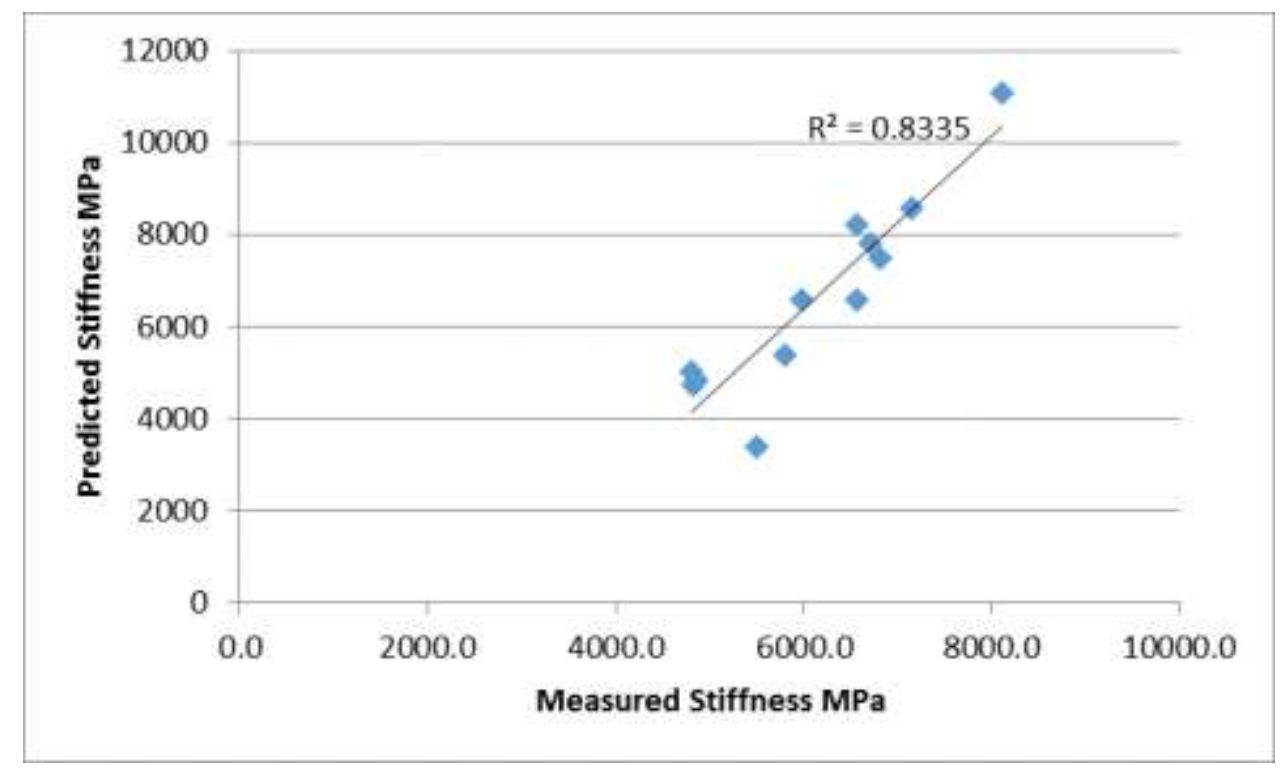

Figure 6: Measured and Predicted Stiffness for Brown's Model

A statistical correlation between the four ratios and the stiffness has been made attempting to predict the stiffness, see equation 10 below:

$$
E=4412-245 C A+337 F A c+573 C_{f} / F_{c}+1784 F / C
$$

The measured and predicted values of stiffness are shown in Figure 7. 


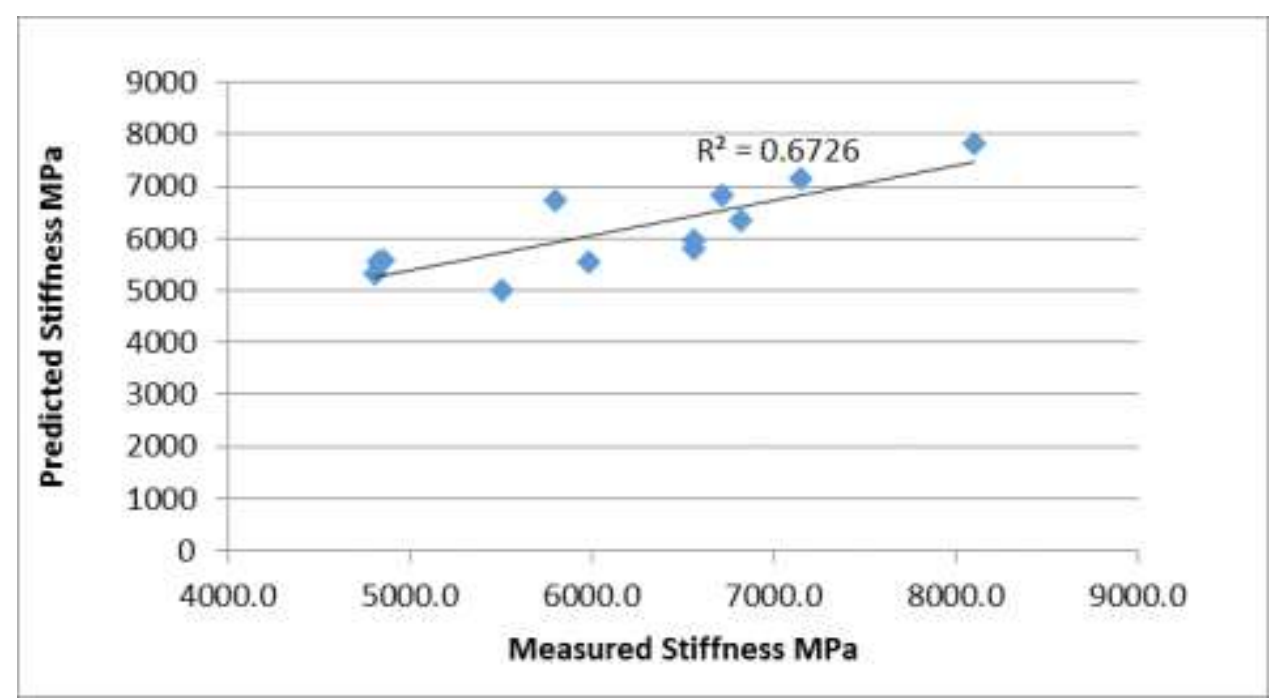

Figure 7: Measured and Predicted Stiffness for the new model

\section{CONCLUSION}

Packing of aggregate is a very important factor that will be affected by changing the aggregate gradation and will change the mixture properties. Thirteen different aggregate gradations have been chosen to understand the effect of changing it on the stiffness of the mixtures. Indirect Tensile Stiffness Modulus Test (ITSM) was carried out to measure the stiffness. Two Bailey ratios and two new introduced ratios were used in the gradation analysis to understand the structural arrangement of the particles. It has been noticed that these ratios has the effect on the density of the mixture and then a reasonable relationship found between these ratios and the stiffness.

\section{ACKNOWLEDGMENT}

The authors highly appreciate the efforts of the Ministry of Higher Education in Iraq The University of Baghdad for funding this project.

\section{REFERENCES}

BROWN, S. 1978. Material characteristics for analytical pavement design. Developments in highway pavement engineering, 1, 41-92.

FULLER, W. \& THOMPSON, S. 1907. The laws of proportioning concrete. Trans Am Soc Civil Eng 59:67.

KIM, S., ROQUE, R., GUARIN, A. \& BIRGISSON, B. 2006. Identification and Assessment of the Dominant Aggregate Size Range (DASR) of Asphalt Mixture (With Discussion). Journal of the Association of Asphalt Paving Technologists, 75.

MIRANDA, B. L. 2012. Gradation-Based Framework for Asphalt Mixtures. KTH, Royal Institute of Technology. 
NIJBOER, L. W. 1948. Plasticity as a factor in the design of dense bituminous road carpets, Elsevier Pub. Co.

OLARD, F. \& PERRATON, D. 2010. On the optimization of the aggregate packing characteristics for the design of high-performance asphalt concretes. Road Materials and Pavement Design, 11, 145-169.

TALBOT, A. N. \& RICHART, F. E. 1923. THE STRENGTH OF CONCRETE-ITS RELATION TO THE CEMENT, AGGREGATES AND WATER. Illinois Univ Eng Exp Sta Bulletin.

THOM, N. 2008. Principles of pavement engineering.

VAVRIK, W. R. 2002. Bailey method for gradation selection in hot-mix asphalt mixture design, Transportation Research Board, National Research Council.

VAVRIK, W. R., PINE, W. J., HUBER, G., CARPENTER, S. H. \& BAILEY, R. 2001. The bailey method of gradation evaluation: the influence of aggregate gradation and packing characteristics on voids in the mineral aggregate (with discussion). Journal of the Association of Asphalt Paving Technologists, 70. 